\title{
High density SNP and SSR-based genetic maps of two independent oil palm hybrids
}

Ngoot-Chin Ting 1,4, Johannes Jansen², Sean Mayes ${ }^{3}$, Festo Massawe ${ }^{4}$, Ravigadevi Sambanthamurthi ${ }^{1}$, Leslie Cheng-Li Ooi ${ }^{1}$, Cheuk Weng Chin ${ }^{5}$, Xaviar Arulandoo ${ }^{6}$, Tzer-Ying Seng ${ }^{5}$, Sharifah Shahrul Rabiah Syed Alwee ${ }^{5}$, Maizura Ithnin ${ }^{1}$ and Rajinder Singh ${ }^{1 *}$

\begin{abstract}
Background: Oil palm is an important perennial oil crop with an extremely long selection cycle of 10 to 12 years. As such, any tool that speeds up its genetic improvement process, such as marker-assisted breeding is invaluable. Previously, genetic linkage maps based on AFLP, RFLP and SSR markers were developed and QTLs for fatty acid composition and yield components identified. High density genetic maps of crosses of different genetic backgrounds are indispensable tools for investigating oil palm genetics. They are also useful for comparative mapping analyses to identify markers closely linked to traits of interest.

Results: A $4.5 \mathrm{~K}$ customized oil palm SNP array was developed using the Illumina Infinium platform. The SNPs and 252 SSRs were genotyped on two mapping populations, an intraspecific cross with 87 palms and an interspecific cross with 108 palms. Parental maps with 16 linkage groups (LGs), were constructed for the three fruit forms of E. guineensis (dura, pisifera and tenera). Map resolution was further increased by integrating the dura and pisifera maps into an intraspecific integrated map with 1,331 markers spanning 1,867 cM. We also report the first map of a Colombian E. oleifera, comprising 10 LGs with 65 markers spanning $471 \mathrm{cM}$. Although not very dense due to the high level of homozygosity in E. oleifera, the LGs were successfully integrated with the LGs of the tenera map. Direct comparison between the parental maps identified 603 transferable markers polymorphic in at least two of the parents. Further analysis revealed a high degree of marker transferability covering 1,075 cM, between the intra- and interspecific integrated maps. The interspecific cross displayed higher segregation distortion than the intraspecific cross. However, inclusion of distorted markers in the genetic maps did not disrupt the marker order and no map expansion was observed.
\end{abstract}

Conclusions: The high density SNP and SSR-based genetic maps reported in this paper have greatly improved marker density and genome coverage in comparison with the first reference map based on AFLP and SSR markers. Therefore, it is foreseen that they will be more useful for fine mapping of QTLs and whole genome association mapping studies in oil palm.

Keywords: Elaeis guineensis, E. oleifera, Interspecific, Intraspecific, Comparative mapping

\section{Background}

The oil palm is a diploid $(2 n=2 x=32)$, outbreeding monocot with a genome of approximately 1.8 billion base-pairs [1]. The genus Elaeis consists of two species, Elaeis guineensis from Africa and E. oleifera from South America. E. guineensis has three fruit forms, dura, pisifera and tenera. Tenera, a hybrid of the two other fruit forms,

\footnotetext{
* Correspondence: rajinder@mpob.gov.my

${ }^{1}$ Advanced Biotechnology and Breeding Centre, Malaysian Palm Oil Board (MPOB), No. 6, Persiaran Institusi, Bandar Baru Bangi 43000, Kajang, Selangor, Malaysia

Full list of author information is available at the end of the article
}

is mainly grown in commercial plantations because of its higher oil yield compared to the dura, E. oleifera and interspecific hybrids of E. oleifera and E. guineensis. The pisifera palm is generally female sterile and exhibits fruit bunch abortion.

The Malaysian national average palm oil yield (OY) has stagnated at $\sim 3.9 \mathrm{t} / \mathrm{ha} / \mathrm{yr}$ for the past 20 years. The stagnation is particularly challenging to the Malaysian palm oil industry in its efforts to improve productivity. Land is scarce and there is no more than an additional 1.3 million ha for oil palm cultivation [2]. One important 
approach to bypass this constraint is to breed for higher yields. It has been postulated that oil palm can produce OY up to $18.2 \mathrm{t} / \mathrm{ha} / \mathrm{yr}$ [3]. In fact, impressive progress has already been made in this direction with calculated $\mathrm{OY}$ as high as $12.2 \mathrm{t} / \mathrm{h} / \mathrm{yr}$ [4] and $13.6 \mathrm{t} / \mathrm{h} / \mathrm{yr}$ [5] in individual palms and experimental plots. This demonstrates the genetic potential of oil palm. Also the fatty acid composition (FAC) of palm oil has received a great deal of interest. About half of the palm oil is composed of saturated oil with $44.3 \%$ palmitic acid (C16:0) and $4.6 \%$ stearic acid (C18:0) [6]. As more unsaturated palm oil is desirable in some instances, one idea is to increase the proportion of oleic (C18:1) and linoleic (C18:2) acids.

For molecular breeding of oil palm, a number of QTLs associated with yield traits and FAC have previously been identified using restriction fragment length polymorphism (RFLP), amplified fragment length polymorphism (AFLP) and simple sequence repeat (SSR) markers [7-9]. However, marker density of the genetic maps remained low with large gaps between the markers and QTLs, leading to limited application of markers in breeding. Many more markers can now easily be identified using single nucleotide polymorphisms (SNPs) as already demonstrated in other plants. In apple (Malus pumila Mill.), marker density was dramatically improved from 1 per $3.8 \mathrm{cM}$ to 1 per $0.5 \mathrm{cM}$ by mapping 2,272 SNP markers [10]. The average map distance between markers for chickpea (Cicer arietinum L.) was also improved to 1 every $1.7 \mathrm{cM}$ by inclusion of 697 SNP markers compared to previous reports [11]. There were also efforts to improve marker density by integrating maps from different crosses using SNP markers as bridges between maps, as in grape [12], potato [13], oilseed rape [14] and peach [15]. In oil palm, SNP markers are promising as they occur at relatively high frequency. Riju et al. found $16.8-17.5$ SNPs/kbp in oil palm ESTs [16]. Therefore, SNPs can be used to improve genetic maps.

The present study was undertaken to improve the marker density of genetic maps from two separate mapping populations namely an E. oleifera $\times$ E. guineensis (tenera) interspecific cross and a dura $\times$ pisifera intraspecific cross which segregate for FAC and for yield components, respectively $[9,17]$. The SNP markers developed to help with this were derived from oil palm genomic sequences [18]. A small number of these had previously been sucessfully tested using cleaved amplified polymorphic sequences (CAPS) and Illumina GoldenGate ${ }^{\bullet}$ assays [19,20]. Along with development of a number of automated genotyping platforms, it is now possible to assay a large set of SNP markers in several mapping populations simultaneously.

In recent years, many publications in potato [13], oilseeds [14], peach [15], tomato [21] and soybean [22] indicated the usefulness and reliability of the Illumina Infinium high throughput genotyping platform. In this study, an Infinium array of 4,451 oil palm customized SNPs, namely, OPSNP3, was used to develop saturated maps. These SNPs were selected based on their unique positions and widedistribution on the published pisifera genome scaffolds generated from the whole genome sequencing project [1]. The high density genetic maps for the two crosses presented here can therefore improve the likelihood of locating markers more tightly linked to FAC and yield components and to ensure complete and even genome coverage for such analyses. At the same time, the study also cross-mapped a number of SSR-anchor markers from other published maps $[8,23,24]$ to facilitate a comparison of maps developed from different genetic backgrounds.

Comparative mapping based on model plants or among closely related species has been reported for many plants, such as Phaseolus vulgaris L. and Glycine max [25,26], Populus alba and P. nigra [27], Pinus lambertiana Dougl. and Pinus taeda L. [28], Eucalyptus grandis, E. urophylla and E. globulus [29] using various marker types. Different levels of conserved synteny were detected across the species, depending on their taxonomic distance. Comparative mapping is a very reliable method to establish the orthology of genomic regions in other species [30,31] which can lead to gene discovery [31-34]. The extent of genome similarity and diversification between the intra- and interspecific hybrids of oil palm is not well documented. Mapping a common set of SNP and SSR markers onto their genetic maps facilitates direct comparison between the two genomes and makes it possible to establish the similarity between them. Homologous markers identified across the two hybrid maps can also be useful for further fine mapping, particularly for regions associated with traits of interest.

\section{Methods \\ Mapping populations}

Two mapping populations were obtained from different breeding backgrounds hereafter referred to as P2 and OxG. The family information and mapping strategies applied are illustrated in Figure 1. The P2 population is an intraspecific cross between Deli dura and Yangambi pisifera, a high yielding cross [35] from Federal Land Development Authority Malaysia (FELDA) which uses both parents extensively in its breeding programs. Preliminary parental maps containing AFLP, RFLP and SSR markers have been reported $[17,36]$. The Yangambi pisifera parent has also been crossed with other Deli duras to develop an AFLP and SSR-based genetic linkage map [24]. The OxG population is an interspecific cross of a Colombian E. oleifera and a Nigerian tenera, obtained from United Plantations (UP) Berhad. A preliminary linkage map with AFLP, RFLP and a small number of SSR markers was previously constructed for the tenera parent. 

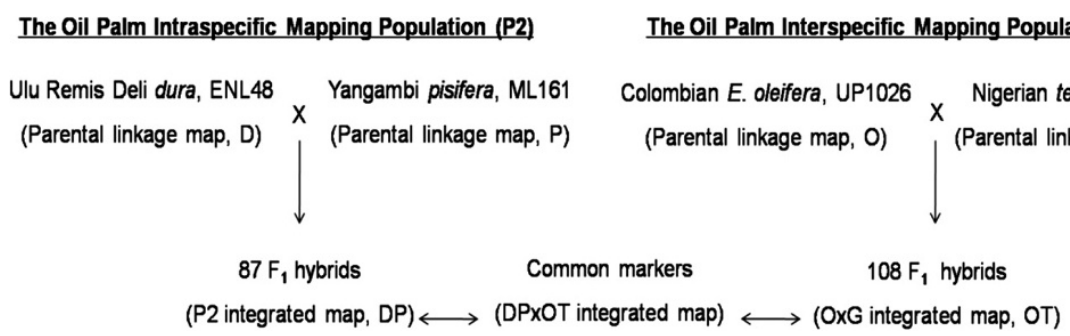

$(\mathrm{P} 2$ integrated map, DP) $\longleftrightarrow$ (DPxOT integrated map) $\longleftrightarrow$ (OxG integrated map, OT)
The Oil Palm Interspecific Mapping Population (OxG)

Colombian E. oleifera, UP1026

(Parental linkage map, O) $\mathrm{X}$

Nigerian tenera, T128

(Parental linkage map, T)

Figure 1 Mapping populations. The mapping strategy was to first construct a genetic linkage map for each parental palm in the P2 intraspecific cross dura (ENL48) x pisifera (ML161) and interspecific cross of E. oleifera x E. guineensis (OxG). A bi-parental integrated map was also constructed for P2 (labeled DP) and OxG (labeled OT). Subsequently, the DPxOT (/T) integrated map was constructed to show the common markers across the two populations.

Markers broadly linked to QTLs associated with FAC were reported for OxG [9].

\section{Oil palm DNA extraction}

Genomic DNA was extracted from frozen spear leaves (stored at $-80^{\circ} \mathrm{C}$ ) of palms using the modified CTAB method [37]. The DNA concentration and purity were measured using the NanoDrop spectrophotometer (NanoDrop Technologies Inc., Wilmington, DE) and visualized by $1 \%$ agarose gel electrophoresis. For SSR genotyping, DNA was diluted to $50 \mathrm{ng} / \mathrm{ul}$. However, for the high throughput SNP assay using the Illumina platform, the DNA was first quantified using the Quant-i $T^{\mathrm{mM}}$ PicoGreen $^{\curvearrowleft}$ dsDNA Reagent (Invitrogen, Carlsbad, CA) and subsequently normalized to $50 \mathrm{ng} / \mathrm{ul}$.

\section{SNP assay}

The SNP markers were derived from a collection of approximately 400,000 genomic sequences obtained from sequencing the hypomethylated regions of 8 palms using GeneThresher $^{\mathrm{Tm}}$ technology [18]. The criteria used to identify SNPs were - (1) the consensus sequence contained $40-60 \%$ GC nucleotides, (2) putative SNPs in either allele were supported by at least 2 reads, (3) to have at least 100 bases with no other SNPs within the 25-base window on the left and right of the target SNP to ensure that a 50-mer specific probe could be designed within the flanking region and (4) SNPs in repetitive or duplicated regions were removed. A small subset of SNPs produced were tested using CAPS assay $[19,38]$ to determine efficiency of the markers. Further filtering was done by mapping the sequences containing SNPs to the E. guineensis genome scaffolds [1]. SNP markers that mapped uniquely to the assembled genome were considered for further analysis. Of these, approximately 5,000 SNPs that were evenly distributed across the assembled genome were selected. A small panel of 96 SNPs (randomly chosen) were then validated on several mapping populations and a small set of samples from MPOB's germplasm collections using the Illumina GoldenGate ${ }^{\oplus}$ assay [20]. Upon validation of the genotyping efficiency, a final set of 4,451 SNPs, with a minimum Illumina design score of 0.9 were selected for developing the oil palm specific SNP array - OPSNP3.

The probes were printed on the 24-sample Infinium HD iSelect BeadChips platform (Illumina Inc., San Diego, CA). The sequence information for the SNP markers is available at http://genomsawit.mpob.gov.my with the nomenclature of SNPM (SNP marker) + a five digit number. The OPSNP3 array was used to genotype the P2 and OxG mapping populations using the Illumina Infinium II BeadChip platform. The SNP hybridization assay was carried out following the Illumina protocol (Illumina Inc., San Diego, CA). The DNA (200 ng) was isothermally amplified and incubated overnight followed by an enzymatic fragmentation. The fragments were purified before hybridizing onto the probes. After hybridization, allelic specificity was conferred by single base extension and fluorescent staining (green and red), with the signals detected by the Illumina BeadArray Scanner.

\section{SSR genotyping assay}

In this study, additional oil palm SSR markers were generated using the M13-tailed primers (5'CACGACGTTGT AAAACGAC3') as described by Ting et al. [17]. A separate M13 dye labelled primer was synthesized (forward primer-M13 and HEX-/ 6-FAM-/ NED-M13). The genotyping assay was carried out using the ABI3100 genetic analyzer (Applied Biosystems, Warrington, UK).

\section{SNP and SSR data analysis}

Polymorphic SNPs were scored $a a, a b$ or $b b$ according to the default clustering algorithm of GenomeStudio ${ }^{\circ}$ Data Analysis Software (Illumina Inc., San Diego, CA). However, each genotype call was reassessed manually and rescored if necessary. SNPs that did not amplify or form well-separated clusters were excluded. Polymorphic SSRs were scored based on the observed segregation profiles (no.1, 5, 8 and 9) as reported previously [17]. In profile 1, heterozygous and homozygous genotypes for a segregating allele were scored as $a b$ and $a a$. In profile 5, 
genotypes of two co-segregating alleles were scored as $a a$ (homozygous for the first allele), $a b$ (heterozygous) and $b b$ (homozygous for the second allele). In profile 8 , genotypes of three co-segregating alleles were scored as $a a$ (homozygous for the common allele in both parents), $a b$ (similar to the first parental genotype), $a c$ (similar to the second parental genotype) and $b c$ (heterozygote for the two different alleles in both parents). In profile 9, four co-segregating alleles were labeled as $a$ and $b$ for the two alleles in the first parent and $c$ and $d$ in the second parent. The observed genotypes in the hybrids were scored as $a c, b c, a d$ and $b d$ based on the combinations of the alleles. The data was incorporated into the existing data sets of P2 and OxG.

\section{Construction of the high density linkage maps}

Linkage map analysis was performed separately for P2 and OxG using JoinMap ${ }^{\oplus} 4.1$ [39]. Both data sets were coded according to the format for cross-pollinator (CP). Chi-square analysis ( $x^{2}$ test) was carried out to identify markers showing high levels of segregation distortion. Those with distorted ratios at $\mathrm{p}<0.0001$, or with $\geq 10 \%$ missing data (call rates $<90 \%$ ), were excluded according to the criteria reported by Singh et al. [9].

The current software allows the construction of the two parental maps and the integrated map simultaneously using the maximum likelihood (ML) method [40]. The process of grouping markers and finding their best possible position was carried out as previously described [17]. Essentially the steps taken were as follow: (1) Linkage groups (LGs) were formed at a recombination frequency (RF) threshold of 0.2 , (2) Haldane mapping function was used to transform the RF between markers into a map distance in centiMorgan (cM), (3) markers with a nearest neighbor stress (N.N. Stress) value $>4 \mathrm{cM}$ were discarded from each LG (this would be expected to eliminate markers with unlikely genotypes, such as double recombination events in short genetic distances) and, (4) stability of the marker order on each LG was confirmed by altering the markers and comparing the results using MapChart 2.2 [41]. All other parameters applied in building the maps and ordering the markers used the default settings.

Integration of the cross-population P2 and OxG maps was carried out based on common markers using an extension to multiple populations of the method used for ordering markers in a single population [40]. Map distance was calculated using multipoint maximum likelihood via GenStat 15 [42]. The P2, OxG and integrated maps were aligned and compared using MapChart 2.2.

\section{Segregation distortion}

Chi-square analysis ( $\chi^{2}$ test) was carried out for each mapped marker (except for markers with segregation profiles 5, 8 and 9). The segregation ratios of the maternal palm (for markers with segregation profile $1<a b x a a>$ ) and the paternal palm (for markers with segregation profile $1<a a x a b>$ were determined by calculating the proportion of alleles obtained from the respective first grandparents. The assignment 'first grandparent' versus 'second grandparent' depended on the phasing of markers (JoinMap 4.1 [39], when the LGs were formed). For a marker with segregation type $<a b x a a>$ and phase $\{0-\}$ $(\{1-\})$, the individual scored $a a$ inherits the maternal allele from the maternal first (second) grandparent, whereas for an individual scored $a b$ the maternal allele is inherited from the maternal second (first) grandparent. Hereafter, the 'first grandparent' will be referred to as grandmother. In order to get a better understanding of the genomic regions involved in segregation distortion, the proportion of alleles inherited from the respective grandmothers were estimated for both populations and plotted against the positions of markers on the linkage map.

\section{Results}

\section{Oil palm SNP (OPSNP3) array}

A total of 4,451 customized oil palm SNPs were genotyped on the P2 intraspecific and OxG interspecific mapping populations using the Illumina Infinium platform. The proportion of single base changes observed was $61 \%(2,708)$ transitions $(1,333 \mathrm{~A} / \mathrm{G}$ and $1,375 \mathrm{~T} / \mathrm{C}$ ) and $39 \%(1,743)$ transversions $(477 \mathrm{~A} / \mathrm{C}$, $462 \mathrm{~T} / \mathrm{G}, 470 \mathrm{~A} / \mathrm{T}, 334 \mathrm{C} / \mathrm{G})$. The number of transition SNPs were $\sim 1.5$ times the number of transversions, close to the values found in chickpea [11], melon [43] and cacao [44].

\section{Assessment of informative markers}

The SNP genotyping results showed very high call rates which ranged from 97 to $98 \%$ for P2 and 91 to $97 \%$ for OxG, indicating the efficiency of the genotyping platform used. The majority of the SNPs were clustered in clearly defined profiles with only a small number (37 in P2 and 58 in OxG) displaying insufficient separation of the allele clusters. These SNPs were excluded from further analysis. A total of 3,082 and 3,299 of the SNPs were monomorphic in $\mathrm{P} 2$ and $\mathrm{OxG}$, respectively; they were also excluded from linkage analysis in the bi-parental populations. The P2 intraspecific hybrid revealed more informative SNPs (30\%) than the OxG interspecific hybrid (24\%).

In P2, a total of 1,324 informative SNPs and an additional 53 SSRs were identified and incorporated into the existing data set (342 SSRs) previously described [17]. The final data set used for linkage analysis is summarized in Table 1. Of the 1,324 SNPs, 1,109 segregated in two clusters ( $a a$ and $a b$ ) corresponding to either homozygotes or heterozygotes, and 215 co-segregated in three clusters $(a a, a b$ and $b b)$. In the SSR analysis, profile 1 (299 SSRs), profile 5 (21 SSRs), profile 8 (53 SSRs) and 
Table 1 Summary of SSR and SNP markers in P2 and OxG mapping populations

\begin{tabular}{|c|c|c|c|c|c|c|}
\hline & \multicolumn{3}{|c|}{ P2 } & \multicolumn{3}{|c|}{ OxG } \\
\hline & SNP & SSR & Sub-total & SNP & SSR & Sub-total \\
\hline \multicolumn{7}{|c|}{$\begin{array}{l}\text { Numbers of } \\
\text { polymorphic alleles: }\end{array}$} \\
\hline 1 (profile 1) & 1,109 & 299 & 1,408 & 1,064 & 290 & 1,354 \\
\hline 2 (profile 5) & 215 & 21 & 236 & 1 & 0 & 1 \\
\hline 3 (profile 8) & - & 53 & 53 & 0 & 6 & 6 \\
\hline 4 (profile 9) & - & 22 & 22 & 0 & 20 & 20 \\
\hline Sub-total & 1,324 & 395 & 1,719 & 1,065 & 316 & 1,381 \\
\hline \multicolumn{7}{|c|}{ Segregation distortion: } \\
\hline$p<0.1$ & 158 & 60 & 218 & 375 & 87 & 462 \\
\hline$p<0.05$ & 104 & 37 & 141 & 243 & 68 & 311 \\
\hline$p<0.01$ & 10 & 6 & 16 & 120 & 40 & 160 \\
\hline$p<0.005$ & 3 & 4 & 7 & 93 & 31 & 124 \\
\hline$p<0.001$ & - & - & - & 23 & 9 & 32 \\
\hline$p<0.0005$ & - & - & - & 5 & 3 & 8 \\
\hline Ungrouped & 38 & 26 & 64 & 29 & 22 & 51 \\
\hline Unmapped & 76 & 238 & 314 & 16 & 140 & 156 \\
\hline Mapped & 1,210 & 131 & 1,341 & 1,020 & 154 & 1,174 \\
\hline
\end{tabular}

profile 9 (22 SSRs) were observed as previously reported [17]. Polymorphism was higher in the male parent (pisifera), in agreement with previous reports [17]. In OxG, 1,065 polymorphic SNPs and 316 SSRs (including 199 new SSRs) were identified with the majority segregating from the tenera parent. Across these markers, the heterozygosity level for the male parental palm was 0.9 . On the contrary, E. oleifera showed low levels of heterozygosity (0.1) with only 148 polymorphic markers (68 SNPs and 80 SSRs). This also help to explain why only one SNP was polymorphic in both parents of OxG.

In P2, 158 SNPs (12\%) and 60 SSRs (15\%) exhibited segregation distortion at $\mathrm{p}<0.1$, including $\mathrm{p}<0.05$ (104 SNPs and 37 SSRs), $\mathrm{p}<0.01$ (ten SNPs and six SSRs) and $\mathrm{p}<0.005$ (three SNPs and four SSRs) (Table 1). However, most of the markers followed the expected segregation ratios. In OxG, approximately $65 \%$ of the SNPs and 73\% of the SSRs agreed with the expected transmission ratios. The remainder (375 SNPs and 87 SSRs) demonstrated various degrees of distortion at $-\mathrm{p}<0.1$, including $\mathrm{p}<0.05$ (243 SNPs and 68 SSRs), $\mathrm{p}<0.01$ (120 SNPs and 40 SSRs), $\mathrm{p}<0.005$ (93 SNPs and 31 SSRs), $\mathrm{p}<0.001$ (23 SNPs and nine SSRs) and $\mathrm{p}<0.0005$ (five SNPs and three SSRs).

\section{P2 parental maps and intraspecific integrated map}

A total of 1,324 SNP and 395 SSR markers were analyzed for construction of the genetic map in the P2 mapping population. Of these, 1,210 SNPs and 131 SSRs (Table 1) were assembled into the 16 linkage groups (LGs) of the dura (D) and pisifera (P) parental maps (Additional file 1). The number of markers mapped in each LG ranged from 11 to 70 in the $\mathrm{D}$, and 15 to 125 in the P map. The lengths of LG varied from 50 (D16) to $144 \mathrm{cM}$ (D8) and 61 (P5) to $215 \mathrm{cM}$ (P4), respectively. The marker content and length of each LG are shown in more detail in Additional file 2. The resulting P2 parental maps covered 1,469 and 1,917 cM with 622 and 921 markers for D and P, respectively.

In P2, 213 codominant markers (188 SNPs and 25 SSRs) were identified for all 16 LGs. These markers provided multiple anchors for integrating the two parental maps into a high density intraspecific integrated genetic map (labeled DP). The common markers were unevenly distributed among the LGs, with DP1 possessing 31 and DP5 only two markers. Other LGs contained different numbers of the common markers, ranging from 20 to 25 (in three LGs), 15 - 19 (three LGs), 10 - 14 (five LGs) and 5 - 9 (four LGs). The marker order in the DP integrated map was highly consistent with the individual D and $\mathrm{P}$ maps (Additional file 1). The map density increased to 1,331 markers $/ 1,867 \mathrm{cM}$ with an average distance between markers of $1.4 \mathrm{cM}$, reducing the average gap compared to that in $\mathrm{D}(2.4 \mathrm{cM})$ and $\mathrm{P}(2.1 \mathrm{cM})$. However, there were still low density regions with intervals ranging from 11 to $18 \mathrm{cM}$ in LGs DP1, 3, 4, 5, 9, 11, 13, 14 and 15 (Additional file 2).

\section{OxG parental maps and a partial interspecific integrated map}

A total of 1,381 polymorphic markers - 1,065 SNPs and 316 SSRs - were scored in the OxG mapping population and used for linkage analysis. Of these, 51 were ungrouped and 156 were removed due to high stress values $(\geq 4 \mathrm{cM})$. The remaining 1,174 (1,020 SNPs and 154 SSRs) were mapped in the tenera $(\mathrm{T})$ and E. oleifera $(\mathrm{O})$ parental maps. The T map had 16 LGs with T4 the longest group (217 cM) with 140 markers. On the other hand, LG T5 was among the smallest groups with only 24 markers spanning $61 \mathrm{cM}$. By comparison, $\mathrm{T}$ is a remarkably high density map (1,121 markers/1,759 cM) compared with $\mathrm{O}$, which has only 10 sparse LGs with 65 markers/471 cM. Although not very dense, the 10 LGs were successfully integrated with LGs from the T map. The integrated LGs were labeled OT1, 4, 6, 7, 8, 10, 11, 12, 13 and 15. As the majority of markers were from tenera, the integrated LGs are very similar to the $\mathrm{T}$ map (Additional file 1 ).

\section{Genome-wide map comparison between P2 and OxG}

A total of 603 transferable markers (550 SNPs and 53 SSRs) were co-mapped in at least two of the D, P, O and $T$ parental maps. Assembly of these shortlisted markers in a genetic map labeled DPxOT (/T) indicates the conserved level of homology between the two crosses. The 
use of a subset of markers explains why the density of cross-species DPxOT (/T) map is less than the biparental integrated maps (DP and OT). Alignment of each LG in DPxOT (/T) with LG of D, P and DP (P2) and LG of $\mathrm{O}, \mathrm{T}$ and $\mathrm{OT}(\mathrm{OxG})$ is presented in Additional file 1. Comparison of the LGs is also shown via Circos plots (see Additional file 3).

Comparing the two hybrid maps, a total of 450 transferable markers were detected across the P2 and OxG populations covering a total map length of approximately $1,075 \mathrm{cM}$. The transferable markers were well distributed in LGs 3 and 16. However, many other markers were distributed unevenly along the LGs and fragmented into smaller blocks of common markers. The pattern was observed particularly in LGs 9,11 and 15 where two distinct blocks of transferable markers were located at opposite arms of the compared groups. Loci that mapped in between the blocks were unique SNPs and SSRs polymorphic in either $\mathrm{P} 2$ or OxG.

\section{Segregation distortion}

Unequal segregation distortion was observed in the P2 intraspecific and OxG interspecific hybrids. In OxG, 35\% (363 SNPs and 49 SSRs) of the mapped markers showed significant deviation from the expected Mendelian segregation ratios. The distorted SNPs showed no preference for transition or transversion, as the transition/ transversion ratio remained close to 1.7. The segregation distortion observed for SSR markers involved 35 di-, six tri-, three mono-, two tetra-, two compound- and one hexa-nucleotide repeat unit motifs. The distorted SNP and SSR markers were distributed non-randomly among the LGs with more distorted markers $(40-81 \%)$ in LGs OT1, T2, OT4, OT7, OT11, OT13 and OT15. Other LGs showed a lower proportion of distorted markers $(1-23 \%)$. About $50 \%$ of the deviations in the OxG cross were in favor of the tenera parent and the other half biased towards E. oleifera. In contrast, only a few skewed markers (159) were observed in P2. Distorted markers which ranged from 2 to $23 \%$ were observed in 14 LGs, with two LGs (DP13 and 16) free from any distorted marker.

The two LGs in P2 (DP13 and 16) that were free from distorted markers had for both parents a proportion of grandmaternal alleles ranging between $43-54 \%$ (Figure 2). However, for almost all other LGs, many regions deviated considerably from $50 \%$ with values going up to $63 \%$ and down to $33 \%$. Similarly in OxG, LG OT6 showed very little segregation distortion with values between $48-58 \%$ for both parents (Figure 3). In other genomic regions the segregation distortion was considerable with values as high as $68 \%$ and as low as $33 \%$. It has also been observed that markers with segregation ratios differing strongly from $50 \%$ clustered together in specific genomic regions; these may contain genes involved in gamete selection.

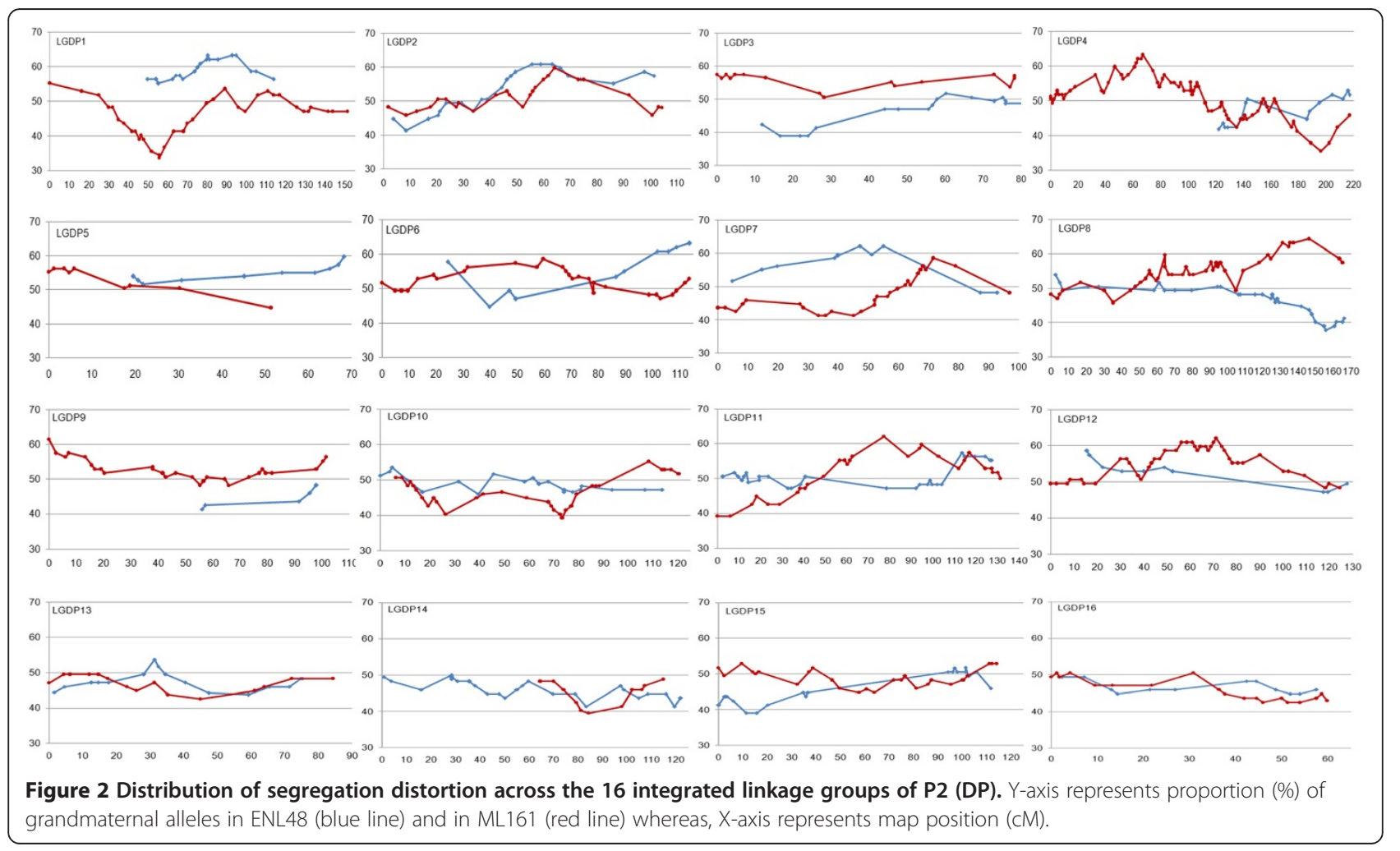




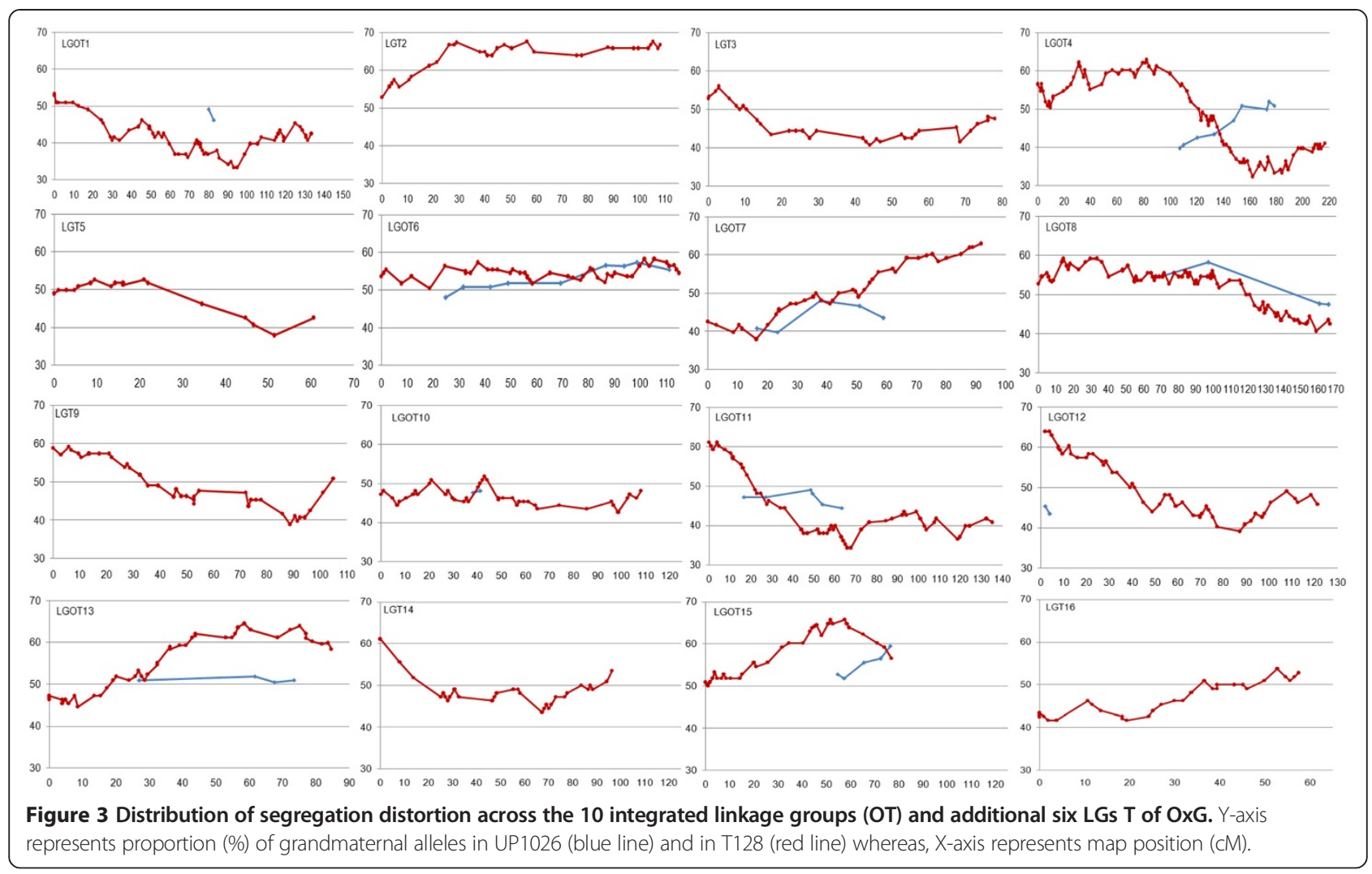

\section{Discussion}

The rapid development of high throughput genotyping techniques makes them very cost effective for assaying large numbers of markers, which is useful in genetic mapping. In this study, the generation of SNP and SSR marker data was greatly accelerated (compared with conventional gel-based methods) using high throughput genotyping platforms. The Illumina Infinium customized OPSNP3 genotyping array and ABI3100 capillary-based fragment analysis allowed us to genotype the same set of SNP and SSR markers in two mapping populations simultaneously and data generation was completed within a short time. Genotyping of 252 SSR and 4,451 SNP markers across 199 palms (including parental palms) of P2 and OxG took less than three months. Furthermore both systems detect co-dominant alleles with differences as small as one base thus minimizing errors in scoring the genotype of markers. The high quality marker data helped in generation of marker linkage groups without obvious inflation of map distances that can be caused by false linkages [45]. The genotyping cost was considered reasonable for the generation of data from a large set of samples and markers.

The genetic maps constructed in this study have thus successfully extended the coverage of the previous tenera map [9] and the dura and pisifera maps [17]. A large set of SNP and SSR markers was used to replace the existing AFLP and RFLP markers to simplify the process of marker ordering in the genetic maps. The average gap between markers in the new maps (estimated as map length over the number of mapped markers) was greatly reduced from one marker every $7.2 \mathrm{cM}$ to one marker every $1.6 \mathrm{cM}$ in tenera $(\mathrm{T}), 5.4 \mathrm{cM}$ to $2.4 \mathrm{cM}$ in dura (D) and $5.5 \mathrm{cM}$ to $2.1 \mathrm{cM}$ in pisifera (P) maps. The gap was down to $1.4 \mathrm{cM}$ in the DP intraspecific integrated genetic map from the previous $1.8 \mathrm{cM}$ [23] for an integrated tenera $\mathrm{x}$ dura map. To the best of our knowledge, the parental and integrated maps presented in this study are the most comprehensive genetic linkage maps published for oil palm to date.

For the OxG interspecific cross, a previous effort failed to construct a map for the female parent, E. oleifera, mainly due to the limited number of AFLP and RFLP markers used [9]. In this study, 10 small LGs with a majority derived from SNP markers were constructed for the E. oleifera parent. Although a large number of SNP markers and a significant number of E. oleifera-derived SSR markers were used, we still could not detect sufficient polymorphisms to saturate the map. This strongly suggests that the Colombian E. oleifera (used in creating the OxG hybrid) is very homozygous. Based upon this finding, future studies should include crossing Colombian $E$. oleifera with a distantly related $E$. oleifera in order to increase the level of heterozygosity in E. oleifera. Several 
rounds of such crossing with different $E$. oleifera may have to be done first, before generating the OxG hybrid. Nevertheless, this study has, for the first time, produced an E. oleifera map, albeit with only limited markers (65 markers/471 cM). Furthermore, the E. oleifera map was successfully integrated with the tenera parental map.

The established high density genetic maps proved useful for comparative mapping analyses. Previously, it was difficult to compare the published genetic maps of oil palm, as different labs used different markers. The markers used in this study also included the published SSRs thus enabling the current maps to be linked to the previously published maps $[8,9,17,23,24]$. Comparisons based on these anchoring markers is presented in Additional file 4. More importantly, SSR markers linked to QTLs for traits such as bunch number, bunch weight, fresh fruit bunch yield, fruit to bunch ratio, kernel to fruit ratio [8] and C16:0 and C18:1 [9], were successfully localized in the maps reported here. The mapping populations in this study also segregate for similar traits and the SSR markers will therefore be useful to indicate the LG locations of the QTLs and the nearby SNPs will help to reveal and validate similar QTL regions for yield components and FAC in P2 and OxG, respectively.

All genetic maps constructed in this study can be directly compared because of the high frequency of transferable markers. Approximately $75 \%$ of the mapped markers were cross-mapped in at least two parental maps of dura, pisifera, E. oleifera and tenera, and serve as good anchors in connecting the maps. The transferable markers will be good starting points to analyze other mapping populations and germplasm. The known map positions will be an added advantage, particularly for estimation of linkage disequilibrium (LD), assessment of genetic diversity and association mapping in oil palm. In oilseed rape for example, over 4,000 SNP markers derived from the genetic map were analyzed on different germplasm collections [14]. Combination of the map information and genotyping data generated from the germplasm analysis allowed the determination of genetic diversity and the extent of LD. From the results, the authors also identified a smaller set of markers suitable for genome-wide association studies. This avoids the use of markers with an uneven or narrow distribution which can severely affect the association of markers to traits of interest. Furthermore, inclusion of transferable markers from specific map locations (such as targeted QTL regions) is useful in identifying and validating marker (s) linked to similar traits in germplasm collections. For example, in wheat, SSR markers associated with QTLs for plant height, spike length, grain yield and other traits on chromosome $4 \mathrm{~A}$, were also associated with the traits in germplasm collections [46].

This study reports the first comparative mapping analysis between intra- and interspecific hybrids of oil palm.
The consistency of marker order and the limited map expansion observed made comparative mapping of the P2 and OxG crosses relatively simple. A high level of congruence between the genetic maps was observed, revealing 57 - 61\% transferable markers between the two hybrid genomes. The transferable markers identified in each LG can help in identifying the corresponding genomic regions in other fruit forms of oil palm, leading to further fine mapping and structural analyses. In Brassica, common QTLs for plant height, flowering time and seed traits were identified in B. rapa, B. napus and B. juncea through synteny analysis [34]. However, the study also examined the expression levels of genes between the species segregating for the QTLs and the counterparts that did not segregate for the same trait. This expression level information, when compared with the whole genome sequencing data of Brassica ssp and A. thaliana led to the discovery of several potentially useful candidate markers for explaining this variation. With the availability of the oil palm genome sequence [1], the anchor markers can be linked to the oil palm physical map. This will facilitate further saturation of the LGs where specific SSRs or SNPs can be designed in areas with large genetic gaps. In fact, the P2 genetic maps constructed in this study showed excellent co-linearity in marker order consistent with the oil palm genome sequence assemblies [1]. Comparison with the whole genome sequence will be very helpful in identifying markers more tightly linked to traits than the ones discovered so far.

Comparative mapping also revealed that the distorted markers mainly occurred in clusters, possibly in the segregation distortion regions (SDRs) [47-50]. However, there is no intimation that SDRs are found at the same map regions or involve the same groups of markers across P2 and OxG. Instead, the SDRs are largely unique to each population and parental palm reflecting the respective polymorphisms and recombination events as has also been observed in potato [13] and barley [48]. The SDRs also may indicate genomic regions involved in selection, e.g. of gametes in the maternal and paternal meioses. A greater tendency for segregation distortion has always been reported in interspecific, or wide crosses in plants [50-52]. Similar results were obtained in this study with the distortion rate higher in the OxG interspecific cross than in the P2 intraspecific cross. The higher segregation distortion in OxG is not surprising as it reflects the substantial genetic divergence and unequal levels of heterozygosity in the two parental palm species. The distortion segregation rate in P2 was similar to that observed in the E. guineensis intraspecific map [23].

In oil palm, SDRs have not been extensively studied compared to the situation in rice, wheat, maize and soybean where they are often associated with genes causing gametic competition [51], gametophytic selection ( $g a$ ) 
[53-56] and sterility [54,57,58]. In maize, preferential fertilization has been frequently reported in pollen with the ga1 allele that mediates pollen - pistil interactions [54]. This results in male gamete competition during transmission which might cause segregation distortion at the ga region. In rice, it was postulated that other chromosomal regions involved in pistil interaction might also interact with $g a$ alleles and cause segregation distortion [52]. However, the results on SDRs in P2 and OxG indicate that in many regions of the genome, there is a preference for one of the grandparental alleles due to some form of selection (either gametic or zygotic). Regions with segregation ratios close to $30 \%$ or $70 \%$ may contain incompatibility genes. These regions are of interest as they may give insight into the selection and evolution of a species [59].

\section{Conclusions}

This study established SNP and SSR high resolution genetic maps for two oil palm hybrids. Genome-wide comparisons between the maps identified transferable markers in the intra- and interspecific integrated maps. The high density genetic maps will be useful for further fine mapping, particularly in finding markers closely linked to QTL associated with traits of interest. The map information therefore can facilitate map-based cloning of the genes, especially through the use of the oil palm genome sequencing data. We foresee these maps being used extensively for QTL detection and whole genome association mapping in oil palm.

\section{Availability of supporting data}

The sequence information for the SNP markers is available at http://genomsawit.mpob.gov.my.

\section{Additional files}

Additional file 1: Alignment of oil palm genetic maps developed for intraspecific (P2) and interspecific (OxG) crosses using common markers. The P2 bi-parental integrated (DP), dura parental (D) and pisifera parental (P) maps are shown on the left and OxG bi-parental integrated $(\mathrm{OT})$, E. oleifera parental $(\mathrm{O})$ and tenera parental (T) maps on the right. The integrated map of P2 and OxG is shown at the centre, labeled DPXOT/T. Haldane genetic distance $(\mathrm{CM})$ is indicated by the ruler on the left of the map. Common markers that co-mapped across D, P, DP, DPXOT/T and T are indicated in red. Nomenclature for markers is: SNPM (SNP), mEgCIR (genomic SSR from [8,23], sEg (E. guineensis EST-SSR), SMg (E. guineensis genomic-SSR), sMo (E. oleifera genomic-SSR), SPSC (SSR developed from E. guineensis scaffold data). Markers showing distorted segregation are marked by *representing significance, viz., $p<0.1$, ${ }^{* *} p<0.05$, ${ }^{* * *} p<0.01$, ${ }^{* * * *} p<0.005,{ }^{* * * *} p<0.001$ and ${ }^{* * * * *} p<0.0005$.

Additional file 2: Information on P2 (D, P and DP) and OxG (O, T and OT) genetic maps as well as the cross-population integrated map (DPxOT/T).

Additional file 3: A closer view of comparative linkage groups (LGs) of dura (D), pisifera (P), E. oleifera $(\mathrm{O})$ and tenera $(\mathrm{T})$ plotted with Circos [60]. LGs $1-16$ are scaled in Haldane genetic distance (CM) and represented by different color coded lines.
Additional file 4: Comparative linkage groups (LGs) between the current maps and previously published oil palm maps. The P2 integrated map (DP) and OxG integrated map (OT/T) are aligned with maps developed by Billotte et al. [8], Singh et al. [9], Ting et al. [17] and Seng et al. [24] based on common RFLP and SSR markers.

\section{Competing interests}

The authors declare that they have no competing interests.

\section{Authors' contributions}

$\mathrm{N}-\mathrm{CT}, \mathrm{RS}$ and $\mathrm{RS}^{*}$ conceived and designed the experiments. $\mathrm{N}-\mathrm{CT}$ carried out molecular experiments and data analysis. LC-LO and RS ${ }^{*}$ participated in the SNP experimental design and coordination. JJ assisted with the statistical analysis of the data. JJ, SM, FM, RS, CWC, XA, TYS, SSRSA and MI advised on the design of the study and contributed materials as well as reagents. N-CT drafted the manuscript. JJ, SM, FM, RS, RS* and Ml assisted with interpretation of data and edited the manuscript. All authors read and approved the final manuscript.

\section{Acknowledgements}

The authors would like to thank the Director-General of MPOB for permission to publish this paper. Part of the work was carried out at Biometris, Wageningen University and Research Centre, the Netherlands. We thank Dr. Leslie Low Eng $\mathrm{Ti}$ and Codon Genomics Sdn. Bhd. for providing bioinformatics support. We would also like to extend our appreciation to Mr. Andy Chang Kwong Choong for his valuable comments on this manuscript. The project was funded by the Malaysian Palm Oil Board (MPOB).

\section{Author details}

'Advanced Biotechnology and Breeding Centre, Malaysian Palm Oil Board (MPOB), No. 6, Persiaran Institusi, Bandar Baru Bangi 43000, Kajang, Selangor, Malaysia. ${ }^{2}$ Biometris, Wageningen University and Research Centre, P.O. Box 100, 6700 AC, Wageningen, the Netherlands. ${ }^{3}$ Plant and Crop Sciences, Sutton Bonington Campus, University of Nottingham, Sutton Bonington, Loughborough LE12 5RD, Nottingham, UK. ${ }^{4}$ School of Biosciences, University of Nottingham Malaysia Campus, Jalan Broga, 43500, Semenyih, Selangor, Nottingham, Malaysia. ${ }^{5}$ FELDA Agricultural Services Sdn. Bhd., $7^{\text {th }}$ Floor, Balai Felda, Jalan Gurney 1, 54000 Kuala Lumpur, Malaysia. ${ }^{6}$ United Plantations Bhd., Jendarata Estate, 36009 Teluk Intan, Perak, Malaysia.

Received: 12 September 2013 Accepted: 25 March 2014 Published: 27 April 2014

\section{References}

1. Singh R, Ong-Abdullah M, Low ETL, Abdul Manaf MA, Rosli R, Nookiah R, Leslie Ooi CL, Ooi S-E, Chan K-L, Halim MA, Azizi N, Nagappan J, Bacher B, Lakey N, Smith SW, He D, Hogan M, Budiman MA, Lee EK, DeSalle R, Kudrna D, Goicoechea JL, Wing RA, Wilson RK, Fulton RS, Ordway JM, Martienssen RA, Sambanthamurthi R: Oil palm genome sequence reveals divergence of interfertile species in old and new worlds. Nature 2013, 499(7459). 10.1038/ nature12309.

2. Prime Minister's Department: Economic Transformation Programme: A Roadmap for Malaysia (1 Malaysia). Putrajaya: Prime Minister's Department, Malaysia; 2010

3. Corley RHV: What is the upper limit to oil extraction ratio? In Proceedings of the 1996 International oil Palm Conference "Oil and Kernel Production in oil Palm-a Global Perspective: 27-28 September 1996; Kuala Lumpur. Edited by Rajanaidu N, Henson IE, Jalani BS. Selangor: Palm Oil Research Institute of Malaysia; 1998:256-269.

4. Rajanaidu N, Rao V, Halim AH, Ong SH: Genetic resources: new developments in oil palm breeding. Elaeis 1990, 1:1-10.

5. Sharma M, Tan YP: Oil palm breeding programmes and the performance of DxP planting materials at United Plantations Berhad. In Proceedings of Seminar on Sourcing of oil Palm Planting Materials for Local and Overseas Joint Venture. Edited by Rajanaidu N, Jalani BS. Selangor: Palm Oil Research Institute of Malaysia; 1999:118-135. 22-23 July 1996.

6. Malaysian Palm Oil Council and Malaysian Palm Oil Board: Fact Sheets. Selangor: Malaysian palm oil; 2008. 
7. Rance KA, Mayes S, Price Z, Jack PL, Corley RHV: Quantitative trait loci for yield components in oil palm (Elaeis guineensis Jacq.). Theor Appl Genet 2001, 103:1302-1310.

8. Billotte $\mathrm{N}$, Jourjon MF, Marseillac $\mathrm{N}$, Berger A, Flori A, Asmady H, Adon B, Singh R, Nouy B, Potier F, Cheah SC, Rohde W, Ritter E, Courtois B, Charrier A, Mangin B: QTL detection by multi-parent linkage mapping in oil palm (Elaeis guineensis Jacq.). Theor App/ Genet 2010, 120(8):1673-1687.

9. Singh $\mathrm{R}$, Tan SG, Panandam JM, Rahimah AR, Ooi LCL, Low ETL, Sharma M, Jansen J, Cheah SC: Mapping quantitative trait loci (QTLs) for fatty acid composition in an interspecific cross of oil palm. BMC Plant Biol 2009, 9:114.

10. Antanaviciute L, Fernández-Fernández F, Jansen J, Banchi E, Evans KM, Viola R, Velasco R, Dunwell JM, Troggio M, Sargent DJ: Development of a dense SNP-based linkage map of an apple rootstock progeny using the Malus infinium whole genome genotyping array. BMC Genomics 2012, 13:203.

11. Gaur R, Azam S, Jeena G, Khan AW, Choudhary S, Jain M, Yadav G, Tyagi AK, Chattopadhyay D, Bhatia S: High-throughput SNP discovery and genotyping for constructing a saturated linkage map of chickpea (Cicer arietinum L.). DNA Res 2012, 19:357-373.

12. Vezzulli S, Troggio M, Coppola G, Jermakow A, Cartwright D, Zharkikh A, Stefanini M, Grando MS, Viola R, Adam-Blondon A-F, Thomas M, This P, Velasco $R$ : A reference integrated map for cultivated grapevine (Vitis vinifera L.) from three crosses, based on 283 SSR and 501 SNP-based markers. Theor Appl Genet 2008, 117:499-511.

13. Felcher KJ, Coombs JJ, Massa AN, Hansey CN, Hamilton JP, Veilleux CRE, Robin Buell C, Douches DS: Integration of two diploid potato linkage maps with the potato genome sequence. PLOS ONE 2012, 7(4):e36347. doi: 10.1371/journal.pone.0036347.

14. Delourme R, Falentin C, Fomeju BF, Boillot M, Lassalle G, André I, Duarte J, Gauthier V, Lucante N, Marty A, Pauchon M, Pichon J-P, Ribière N, Trotoux G, Blanchard P, Rivière N, Martinant J-P, Pauquet J: High-density SNP-based genetic map development and linkage disequilibrium assessment in Brassica napus L. BMC Genomics 2013, 14:120

15. Martínez-García PJ, Parfitt DE, Ogundiwin EA, Fass J, Chan HM, Ahmad R, Lurie S, Dandekar A, Gradziel TM, Crisosto CH: High density SNP mapping and QTL analysis for fruit quality characteristics in peach (Prunus persica L.). Tree Genetics \& Genomes 2013, 9:19-36.

16. Riju A, Chandrasekar A, Arunachalam V: Mining for single nucleotide polymorphisms and insertions/deletions in expressed sequence tag libraries of oil palm. Bioinformation 2007, 2(4):128-131.

17. Ting NC, Jansen J, Nagappan J, Ishak Z, Chin CW, Tan S-G, Cheah S-C, Singh R: Identification of QTLs associated with callogenesis and embryogenesis in oil palm using genetic linkage maps improved with SSR markers. PLOS ONE 2013, 8(1):e53076. doi: 10.1371/journal.pone.0053076.

18. Budiman MA, Singh R, Low LET, Nunberg A, Citek R, Rohlfing T, Bedell JA, Lakey ND, Martienssen RA, Cheah SC: Sequencing of the oil palm genespace. In Proceedings of the 2005 PIPOC International Palm oil Congress-Agriculture, Biotechnology and Sustainability Conference. Kuala Lumpur: (Unedited): Malaysia Palm Oil Board: 2005:628-639.

19. Ooi LCL, Ong PW, Maizura I, Singh R: Discovery of oil palm SNPs and their application in the characterisation of oil palm genetic resources and breeding materials. In Proceedings of the National Biotechnology Seminar. Kuala Lumpur: The National Biotechnology Division (BIOTEK), MOSTI; 2010.

20. Ooi LCL, Rahman RA, Low LET, Singh R: A 1536-Plex oil Palm SNP set for Genetic Mapping and Identification of Markers Associated with oil Palm Fruit Colour. San Diego: Poster (P0201) presented at the International Plant \& Animal Genome Conference XX; 2012

21. Sim S-C, Durstewitz G, Plieske J, Wieseke R, Ganal MW, Deynze AV, Hamilton $J P$, Buell CR, Causse M, Wijeratne S, Francis DM: Development of a large SNP genotyping array and generation of high-density genetic maps in tomato. PLOS ONE 2012, 7(7):e40563. doi: 10.1371/journal.pone.0040563.

22. Song Q, Hyten DL, Jia G, Quigley CV, Fickus EW, Nelson RL, Cregan PB: Development and evaluation of SoySNP50K, a high-density genotyping array for soybean. PLOS ONE 2013, 8(1):e54985. doi: 10.1371/journal.pone.0054985.

23. Billotte N, Marseillac N, Risterucci AM, Adon B, Brotteir P, Baurens FC, Singh R, Herran A, Asmady H, Billot C, Amblard P, Durrand-Gasselin T, Courtois B, Asmono D, Cheah SC, Rohde W, Charrier A: Microsatellite-based high density linkage map in oil palm (Elaeis guineensis Jacq.). Theor Appl Genet 2005, 110(4):754-765.

24. Seng TY, Siti Hawa MS, Chin CW, Ting NC, Singh R, Faridah QZ, Tan SG, Syed Alwee SSR: Genetic linkage map of a high yielding FELDA Deli x
Yangambi oil palm cross. PLOS ONE 2011, 6(11):e26593. doi: 10.1371/ journal.pone.0026593.

25. McClean P, Mamidi S, McConnell M, Chikara S, Lee R: Synteny mapping between common bean and soybean reveals extensive blocks of shared loci. BMC Genomics 2010, 11:184.

26. McConnell M, Mamidi S, Lee R, Chikara S, Rossi M, Papa R, McClean P: Syntenic relationships among legumes revealed using a gene-based genetic linkage map of common bean (Phaseolus vulgaris L.). Theor Appl Genet 2010, 121:1103-1116.

27. Paolucci I, Gaudet M, Jorge V, Beritognolo I, Terzoli S, Kuzminsky E, Muleo R, Mugnozza GS, Sabatti M: Genetic linkage maps of Populus alba L. and comparative mapping analysis of sex determination across Populus species. Tree Genetics \& Genomes 2010, 6:863-875.

28. Jermstad KD, Eckert AJ, Wegrzyn لال Delfino-Mix A, Davis DA, Burton DC, Neale DB: Comparative mapping in Pinus: sugar pine (Pinus lambertiana Dougl.) and loblolly pine (Pinus taeda L.). Tree Genetics \& Genomes 2011, 7:457-468.

29. Hudson CJ, Kullan ARK, Freeman JS, Faria DA, Grattapaglia D, Kilian A, Myburg AA, Potts BM, Vaillancourt RE: High synteny and colinearity among Eucalyptus genomes revealed by high-density comparative genetic mapping. Tree Genetics \& Genomes 2012, 8:339-352.

30. Duran C, Edwards D, Batley J: Genetic maps and the use of synteny. In Methods in Molecular Biology, Plant Genomics, vol. 513. Edited by Somers DJ, Langridge P, Gustafson JP. New York: Humana Press; 2009:41-55.

31. Li F, Ma C, Chen Q, Liu T, Shen J, Tu J, Xing Y, Fu T: Comparative mapping reveals similar linkage of functional genes to QTL of yield-related traits between Brassica napus and Oryza sativa. J Genet 2012, 91:163-170.

32. Zhang Y, Sledge MK, Bouton JH: Genome mapping of white clover (Trifolium repens L.) and comparative analysis within the Trifolieae using cross-species SSR markers. Theor App/ Genet 2007, 114:1367-1378.

33. Wang CM, Liu P, Yi C, Gu K, Sun F, Li L, Lo LC, Liu XK, Feng F, Lin G, Cao SY, Hong Y, Yin ZC, Yue GH: A first generation microsatellite- and SNP- based linkage map of Jatropha. PLOS ONE 2011, 6(8):e23632. doi: 10.1371/journal. pone.0023632

34. Li X, Ramchiary N, Dhandapani V, Choi SR, Hur Y, Nou I-S, Yoon MK, Lim YP: Quantitative trait loci mapping in Brassica rapa revealed the structural and functional conservation of genetic loci governing morphological and yield component traits in the $A, B$, and $C$ subgenomes of Brassica species. DNA Res 2013, 20(1):1-16.

35. Chin CW, Shuhaimi S: FELDA oil palm planting materials. In Proceedings of Seminar on Sourcing of oil Palm Planting Materials for Local and Overseas Joint Venture. Edited by Rajanaidu N, Jalani BS. Selangor: Palm Oil Research Institute of Malaysia; 1999:71-90.

36. Ting NC, Cheah SC, Zamzuri I, Tan SG, Faridah QZ, Maizura I, Singh R: Statistical mapping of quantitative trait loci controlling the time to first callusing in oil palm (Elaeis guineensis Jacq.) tissue culture. Pertanika J. Trop. Agric. Sci 2006, 29(1\&2):35-45.

37. Doyle JJ, Doyle JL: Isolation of plant DNA from fresh tissue. FOCUS 1990, 12:13-15.

38. Singh R, Maria M, Low ETL, Leslie Ooi CL, Chan PL, Rozana R, Ting NC, Maizura I: Oil palm genomics: a foundation for improved agricultural productivity. In Further Advances in oil Palm Research (2000-2010). Edited by Basri MW, Choo YM, Chan KW. Bangi: Malaysian Palm Oil Board; 2011:202-251.

39. Van Ooijen JW: JoinMap 4, Software for the Calculation of Genetic Linkage Maps in Experimental Populations. Wageningen, Netherlands: Kyazma B.V; 2006.

40. Jansen J: Construction of linkage maps in full-sib families of diploid outbreeding species by minimizing the number of recombinations in hidden inheritance vectors. Genetics 2005, 170(4):2013-2025.

41. Voorrips RE: MapChart: software for the graphical presentation of linkage maps and QTLs. J Hered 2002, 93(1):77-78.

42. VSN International: GenStat for Windows. 15th edition. UK: VSN International, Hemel Hempstead; 2011

43. Blanca JM, Cañizares J, Ziarsolo P, Esteras C, Mir G, Nuez F, Garcia-Mas J, Picó MB: Melon transcriptome characterization: simple sequence repeats and single nucleotide polymorphisms discovery for high throughput genotyping across the species. The Plant Genome 2011, 4:118-131.

44. Allegre M, Argout $X$, Boccara $M$, Fouet $O$, Roguet $Y$, Be'rard $A$, Venin JM, Chauveau A, Rivallan R, Clement D, Courtois B, Gramacho K, Boland-Auge' A, Tahi M, Umaharan P, Brunel D, Lanaud C: Discovery and mapping of a new expressed sequence tag-single nucleotide polymorphism and simple sequence repeat panel for large-scale genetic studies and breeding of Theobroma cacao L. DNA RESEARCH 2012, 19:23-35. 
45. Lucas MR, Diop N-N, Wanamaker S, Ehlers JD, Roberts PA, Close TJ: Cowpea-soybean synteny clarified through an improved genetic map. The Plant Genome 2011, 4(3):218-225.

46. Liu L, Wang L, Yao J, Zheng Y, Zhao C: Association mapping of six agronomic traits on chromosome $4 \mathrm{~A}$ of wheat (Triticum aestivum L.). Molecular Plant Breeding 2010, 1(5). 10.5376/mpb.2010.01.0005.

47. Kumar S, Gill BS, Faris JD: Identification and characterization of segregation distortion loci along chromosome 5B in tetraploid wheat. Mol Genet Genomics 2007, 278:187-196.

48. Li HB, Kilian A, Zhou MX, Wenzl P, Huttner E, Mendham N, McIntyre L, Vaillancourt RE: Construction of a high-density composite map and comparative mapping of segregation distortion regions in barley. Mol Genet Genomics 2010, 284:319-331.

49. Cai J, Zgang X, Wang B, Meiyan Y, Qi Y, Kong L: A genetic analysis of segregation distortion revealed by molecular markers in Lophopyrum ponticum chromosome 7E. J Genet 2011, 90:373-376.

50. Wang G, He QQ, Xu ZK, Song RT: High segregation distortion in maize B73 x teosinte crosses. Genet Mol Res 2012, 11(1):693-706.

51. Peng J, Korol AB, Fahima T, Ro" der MS, Ronin YI, Li YC, Nevo E: Molecular genetic maps in wild Emmer wheat, Triticum dicoccoides: genome-wide coverage, massive negative interference, and putative quasi-linkage. Genome Res 2000, 10:1509-1531.

52. Harushima Y, Kurata N, Yano M, Nagamura Y, Sasaki T, Minobe Y, Nakagahra M: Detection of segregation distortions in an indica-japonica rice cross using a high-resolution molecular map. Theor App/ Genet 1996, 92:145-150.

53. Matsushita S, Iseki T, Fukuta Y, Araki E, Kobayashi S, Osaki M, Yamagishi M: Characterization of segregation distortion on chromosome 3 induced in wide hybridization between indica and japonica type rice varieties. Euphytica 2003, 134:27-32.

54. Zhao B, Deng Q-M, Zhang Q-J, Li J-Q, Ye S-P, Liang Y-S, Peng Y, Li P. Analysis of segregation distortion of molecular markers in $\mathrm{F}_{2}$ population of rice. Acta Genet Sin 2006, 33(5):449-457.

55. Bloom JC, Holland JB: Genomic localization of the maize cross-incompatibility gene, Gametophyte factor 1 (ga1). Maydica 2012, 56:1782.

56. Xu X, Li L, Dong X, Jin W, Melchinger AE, Chen S: Gametophytic and zygotic selection leads to segregation distortion through in vivo induction of a maternal haploid in maize. J Exp Bot 2013, 64(4):1083-1096.

57. Wang C, Zhu C, Zhai H, Wan J: Mapping segregation distortion loci and quantitative trait loci for spikelet sterility in rice (Oryza sativa L.). Genet Res 2005, 86(2):97-106.

58. Baumbach J, Rogers JP, Slattery RA, Narayanan NN, Xu M, Palmer RG, Bhattacharyya ML, Sandhu D: Segregation distortion in a region containing a male-sterility, female-sterility locus in soybean. Plant Sci 2012, 195:151-156.

59. Zhan H, Xu S: Generalized linear mixed model for segregation distortion analysis. BMC Genomics 2011, 12:97.

60. Krzywinski M, Schein J, Birol I, Connors J, Gascoyne R, Horsman D, Jones SJ, Marra MA: Circos: an information aesthetic for comparative genomics. Genome Res 2009, 19(9):1639-1645.

doi:10.1186/1471-2164-15-309

Cite this article as: Ting et al:: High density SNP and SSR-based genetic maps of two independent oil palm hybrids. BMC Genomics 2014 15:309.

\section{Submit your next manuscript to BioMed Central and take full advantage of:}

- Convenient online submission

- Thorough peer review

- No space constraints or color figure charges

- Immediate publication on acceptance

- Inclusion in PubMed, CAS, Scopus and Google Scholar

- Research which is freely available for redistribution 